\title{
Correction to: The MLH1 polymorphism rs1800734 and risk of endometrial cancer with microsatellite instability
}

\author{
Holly Russell ${ }^{1}$, Katarzyna Kedzierska², Daniel D. Buchanan $3,4,5$, Rachael Thomas', Emma Tham ${ }^{6,7}$, Miriam Mints ${ }^{8}$, \\ Anne Keränen ${ }^{9}$, Graham G. Giles ${ }^{10,11,12}$, Melissa C. Southey ${ }^{10,11,12}$, Roger L. Milne ${ }^{10,11,12}$, Ian Tomlinson ${ }^{13}$, \\ David Church², Amanda B. Spurdle ${ }^{14}$, Tracy A. O'Mara ${ }^{14}$ and Annabelle Lewis ${ }^{1,15^{*}}$
}

\section{Correction to: Clinical Epigenetics (2020) 12:102} https://doi.org/10.1186/s13148-020-00889-3

Following publication of the original article [1], an error was identified in the Acknowledgements section. The statement: "The research was funded/supported by the National Institute for Health Research (NIHR) Oxford Biomedical Research Centre (BRC)" should be added.

\begin{abstract}
Author details
${ }^{1}$ Cancer Gene Regulation Group, Wellcome Trust Centre for Human Genetics, University of Oxford, Roosevelt Drive, Oxford OX3 7BN, UK. ${ }^{2}$ Cancer Genomics and Immunology Group, Wellcome Trust Centre for Human Genetics, University of Oxford, Roosevelt Drive, Oxford OX3 7BN, UK. ${ }^{3}$ Colorectal Oncogenomics Group, Department of Clinical Pathology, The University of Melbourne, Melbourne, VIC 3010, Australia. ${ }^{4}$ Genomic Medicine and Family Cancer Clinic, Royal Melbourne Hospital, Parkville, VIC 3010, Australia. ${ }^{5}$ University of Melbourne Centre for Cancer Research, Victorian Comprehensive Cancer Centre, Parkville, VIC 3010, Australia. ${ }^{6}$ Department of Molecular Medicine and Surgery, Karolinska Institutet, Stockholm, Sweden. ${ }^{7}$ Department of Clinical Genetics, Karolinska University Hospital, Stockholm, Sweden. ${ }^{8}$ Department of Women's and Children's Health, Karolinska Institutet, Stockholm, Sweden. ${ }^{9}$ Department of Laboratory Medicine, Division of Pathology, Karolinska Institutet, Karolinska University Hospital, Stockholm, Sweden. ${ }^{10}$ Centre for Epidemiology and Biostatistics, Melbourne School of Population and Global Health, The University of Melbourne, Melbourne, VIC 3010, Australia. ${ }^{11}$ Cancer Epidemiology Division, Cancer Council Victoria, Melbourne, VIC 3004, Australia. ${ }^{12}$ Precision Medicine, School of Clinical Sciences At Monash Health, Monash University,
\end{abstract}

Clayton, VIC 3168, Australia. ${ }^{13}$ Cancer Genetics and Evolution Laboratory, Cancer Research UK Edinburgh Centre, MRC Institute of Genetics \& Molecular Medicine, The University of Edinburgh, Western General Hospital, Crewe Road South, Edinburgh EH4 2XR, UK. ${ }^{14}$ Department of Genetics and Computational Biology, QIMR Berghofer Medical Research Institute, Brisbane, QLD 4006, Australia. ${ }^{15}$ Division of Biosciences, Department of Life Sciences, College of Health and Life Sciences, Brunel University, Kingston Lane, Uxbridge UB8 3PH, UK.

Published online: 01 April 2021

\section{Reference}

1. Russell, et al. Clin Epigenetics. 2020;12:102. https://doi.org/10.1186/ s13148-020-00889-3.

\section{Publisher's Note}

Springer Nature remains neutral with regard to jurisdictional claims in published maps and institutional affiliations. to the material. If material is not included in the article's Creative Commons licence and your intended use is not permitted by statutory regulation or exceeds the permitted use, you will need to obtain permission directly from the copyright holder. To view a copy of this licence, visit http://creativecommons.org/licenses/by/4.0/. The Creative Commons Public Domain Dedication waiver (http://creativeco mmons.org/publicdomain/zero/1.0/) applies to the data made available in this article, unless otherwise stated in a credit line to the data. 